\title{
EXPERIMENTAL BIDIRECTIONAL VENTRICULAR TACHYCARDIA IN THE DOG
}

\author{
BY \\ M. C. MEHTA AND V. N. SHARMA \\ From the Department of Pharmacology, S.M.S. Medical College, Jaipur Rajasthan, India \\ Received March 22, 1963
}

Bidirectional ventricular tachycardia is an uncommon cardiac arrhythmia and reports of only 50 cases have hitherto been published. Levy and Lewis (1911) were the first to notice this arrhythmia during their experimental work on cats, while Schwensen (1922) reported the first case of bidirectional ventricular tachycardia in man. Since then there has been general agreement that this arrhythmia has a serious prognosis. There is also a concensus of opinion on the manner in which the arrhythmia appears.

Bidirectional ventricular tachycardia is characterized by two ventricular complexes of prolonged duration and cardiopathic aberrant shape, which alternate rhythmically in opposite directions. However, this alternation in the direction of complexes is not invariable. According to the classification of Scherf and Kisch (1939) this arrhythmia is of three types.

(1) With diastolic intervals equal to those of regular rhythm but with the QRS complexes always alternating in direction.

(2) With alternation of longer and shorter diastolic intervals as well as that of QRS configurations. In this variety the interval between the complexes that resemble each other is usually equal, and between those that do not resemble each other it is unequal.

(3) With the length of the diastole as well as the shape of the ventricular complexes varying irregularly.

Its genesis is a subject of considerable uncertainty, as many as seven theories having been postulated to explain its mechanism. No experimental work on this matter, or on the manner of production of the arrhythmia has been found in earlier publications on this subject.

\section{MATERIAL AND Methods}

Ventricular ectopic arrhythmias were produced by adrenaline hydrocarbon in 200 mongrel dogs, according, to the method described by Riker et al. (1955). In our experiments it consisted in anæsthetizing mongrel dogs with pentobarbital $30 \mathrm{mg} . / \mathrm{kg}$. intravenously, artificial respiration being instituted by a tracheal injection of $0.1 \mathrm{ml} . / \mathrm{kg}$. of petroleum ether followed by intravenous injection of $30 \mu \mathrm{g} . / \mathrm{kg}$. of adrenaline. The arrhythmias were usually ventricular in origin.

Electrocardiographic tracings of 30 experiments out of 200 showed bidirectional ventricular tachycardia and they were selected for the purpose of this study. Of these 30 animals, 20 were male and 10 were female. Their weights ranged from 4 to $16 \mathrm{~kg}$. with an average of $7 \mathrm{~kg}$. All the tracings were recorded on a Grass ink-writing oscillograph machine and were analysed in detail particularly from the point of view of explaining the mechanism of this arrhythmia.

\section{RESULTS}

The ventricular arrhythmias comprised irregular ventricular ectopic activity, ventricular tachycardia, ventricular fibrillation, and ventricular premature beats. In 30 experiments $(15 \%)$ the electrocardiogram showed bidirectional ventricular tachycardia. The detailed analysis of the representative patterns of this arrhythmia, observed during the course of this study, are described below. 


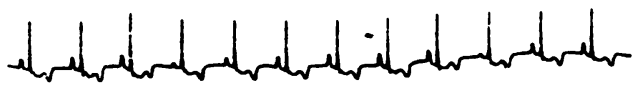

A

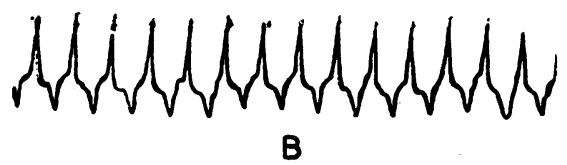

B
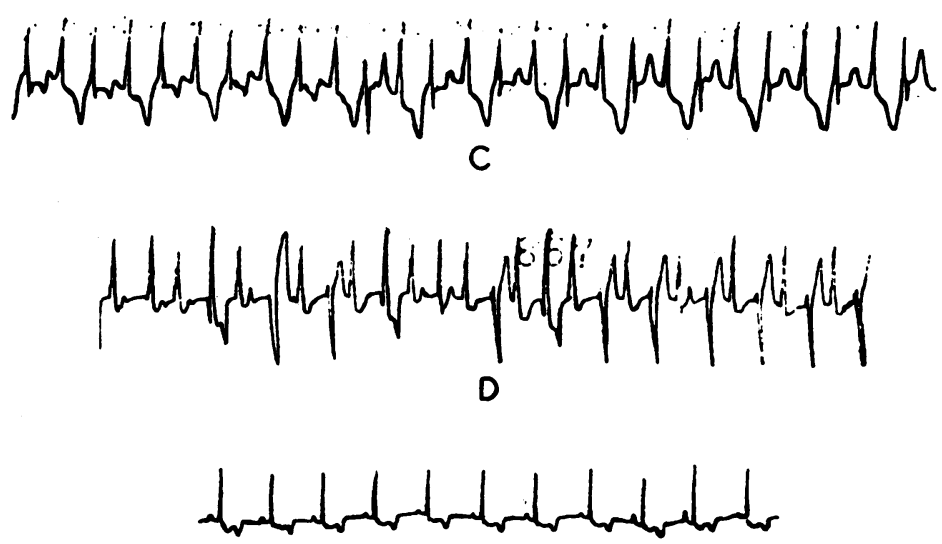

E

FIG. 1.-The series of events described in pattern 1. Ventricular tachycardia is followed by bidirectional ventricular tachycardia (C and D). For details see text.

Pattern 1. Sinus rhythm was recorded in the control electrocardiogram (Fig. 1 A). A run of ventricular tachycardia appeared after performance of the above-mentioned technique. A continuous tracing showed a paroxysm of bidirectional ventricular tachycardia (Fig. $1 \mathrm{C}$ and D). In Fig. $1 \mathrm{D}$ the initial portion showed irregular ectopic ventricular activity and the later part bidirectional ventricular tachycardia: in this later portion ventricular complexes were of aberrant shape and no $\mathbf{P}$ wave could be made out. This was followed after three minutes by regular sinus beats. Six $(20 \%)$ graphs of bidirectional ventricular tachycardia showed this pattern.

Pattern 2. The control graph showed sinus rhythm. After the experiment was performed the tracings recorded bidirectional ventricular tachycardia. Although the complexes were aberrant in shape yet both were preceded by $\mathbf{P}$ waves (Fig. 2 B). The $P$ waves of both the complexes were upright. The $\mathrm{P}$ wave that was followed by downward directed QRS complex was partially merged in the $\mathrm{T}$ wave of the preceding QRS complex. Lead II was continuously recorded until eight minutes later the rhythm changed to sinus tachycardia (Fig. 2 D). In between the recording of strips B and D the graph in Fig. 2 revealed bizarre ventricular ectopic activity (Fig. 2 C). Four experiments $(13 \%)$ showed such pattern.

Pattern 3. The control records had sinus rhythm (Fig. $3 \mathrm{~A}$ ). Following the experiment the graph exhibited the pattern of simultaneous tachycardia (atrial and ventricular) (Fig. 3 B). A paroxysm of bidirectional ventricular tachycardia followed (Fig. $3 \mathrm{C}$ ) after two minutes. The $P$ wave and its $Q R S$ complex were of sinus origin while the $\mathbf{P}^{\prime}$ wave (inverted) and its aberrant $Q R S$ complex were of nodal origin. This was again converted into simultaneous tachycardia to be followed after six minutes by sinus rhythm. Such a pattern was recorded in three experiments $(10 \%)$.

Pattern 4. Sinus arrhythmia was seen in the cardiogram taken before the experiment (Fig. 4 A). 

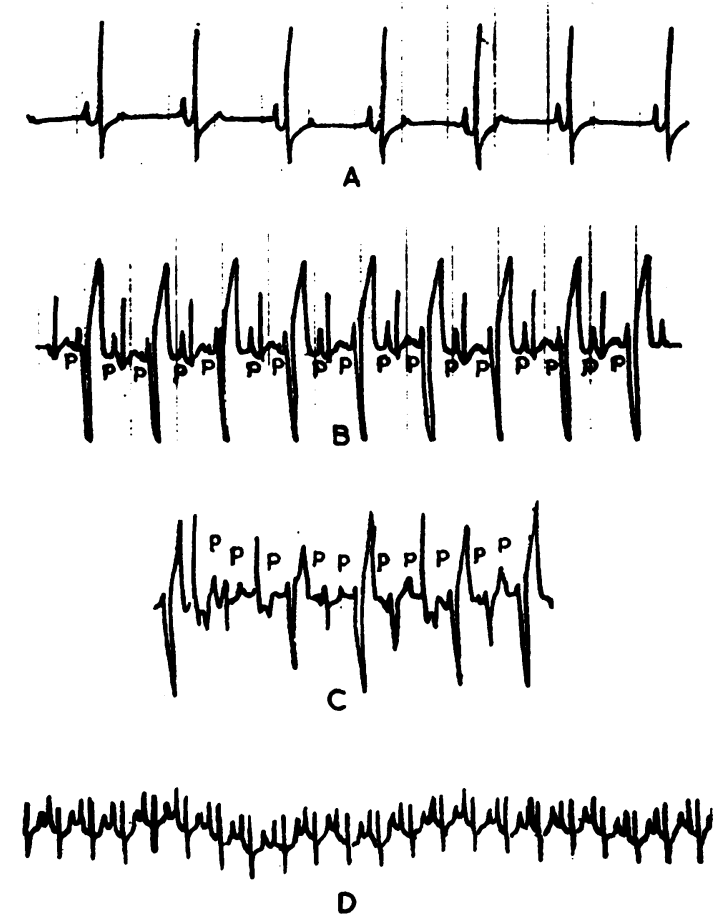

FIG. 2.-The various cardiographic changes observed in pattern 2. Strip B shows bidirectional ventricular tachycardia. For details see text.
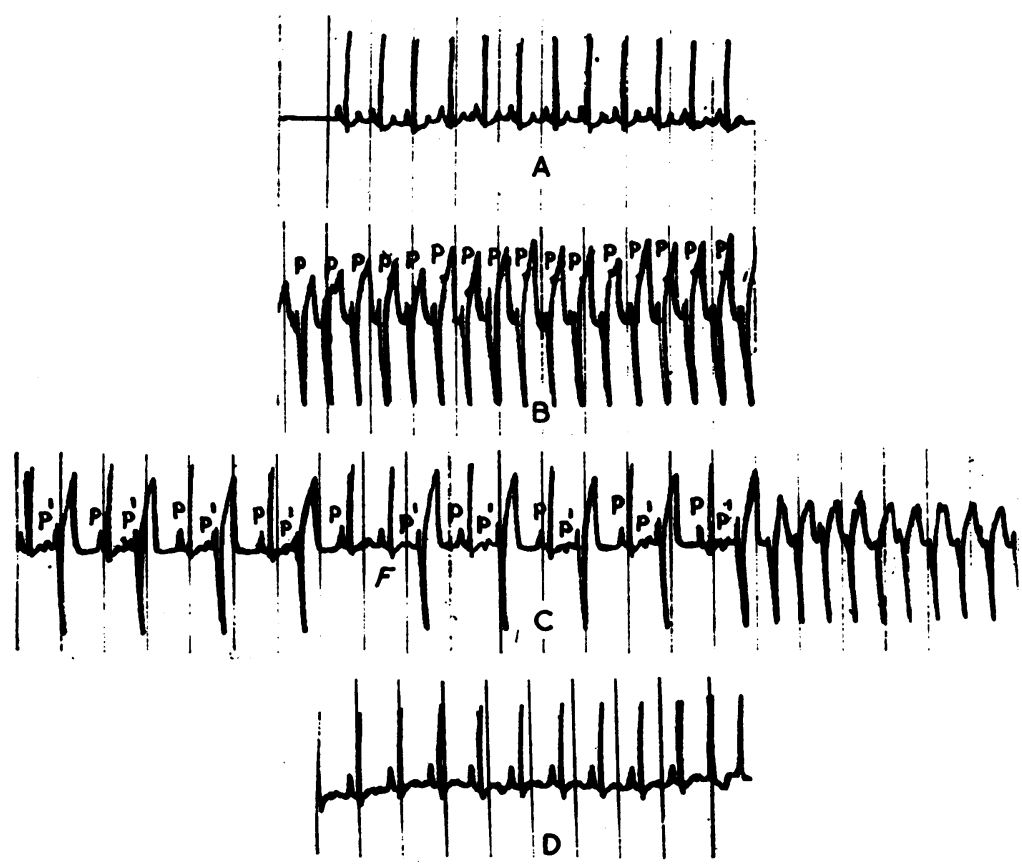

Fig. 3.-An example of pattern 3. Electrocardiographic sequence shows that simultaneous tachycardia (B) was followed by bidirectional ventricular tachycardia (C). For details see text. 


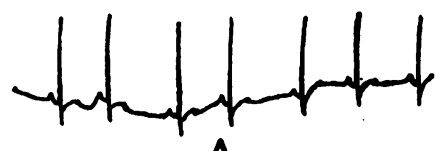

A

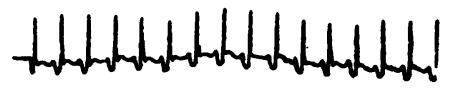

B

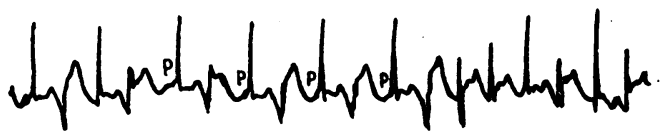

C
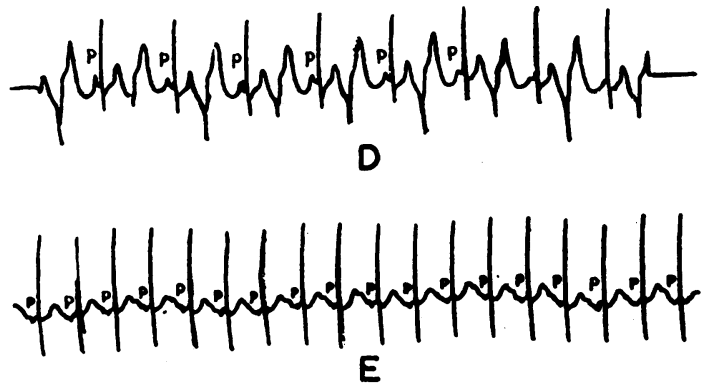

FIG. 4.-Bidirectional ventricular tachycardia of pattern 4 (C and D) following a run of ventricular tachycardia (B). For details see text.
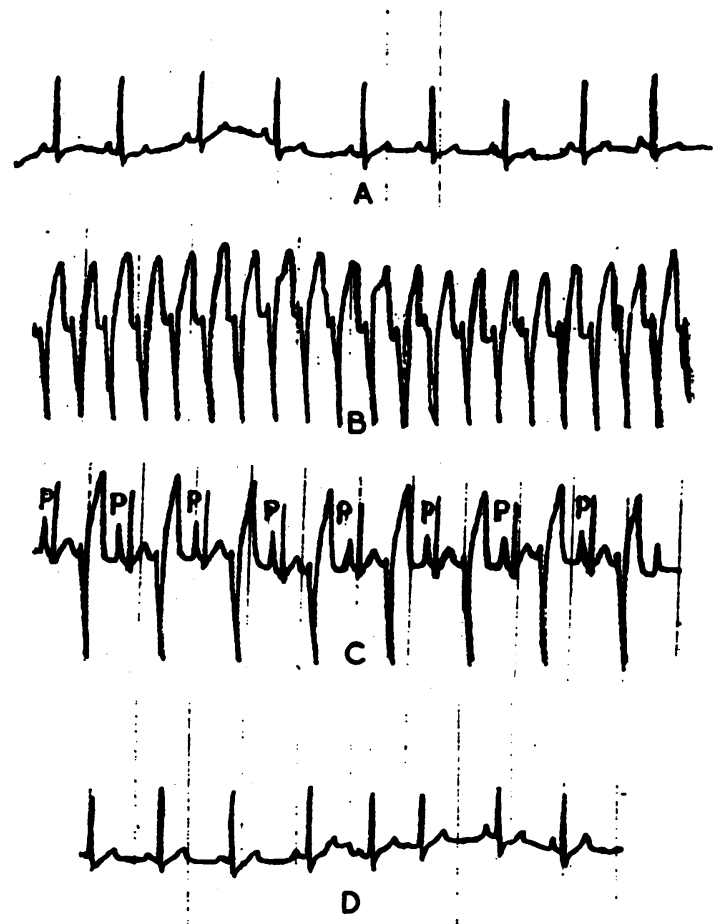

FIG. 5.-Serial changes obtained while recording graphs of pattern 5. Ventricular tachycardia (B) preceded bidirectional ventricular tachycardia (C). For details see text.

One minute after the experiment the graph was that of supraventricular tachycardia (Fig. 4 B) which developed later into that of bidirectional ventricular tachycardia (Fig. $4 \mathrm{C}$ and D). In Fig. $4 \mathrm{C}$ the rhythm was of lower nodal origin (inverted $\mathrm{P}$ waves followed by the normal shaped QRS complex). However, the other QRS complex was of aberrant shape and alternated with one of normal shape. In Fig. $4 \mathrm{D}$ the $\mathrm{P}$ waves became upright and the sequence of $\mathrm{QRS}$ complexes remained the same. Wandering pace-maker in the A-V node was evident in both Fig. $4 \mathrm{C}$ and $\mathrm{D}$. The R-R interval between the upward QRS complex and the downward was smaller than between the downward complex and the next upward complex. In the end (strip E) the rhythm became regular but the $P$ waves remained inverted suggesting a nodal origin. Four experiments $(13 \%)$ exhibited this phenomenon.

Pattern 5. Sinus rhythm was the basic one. Ventricular tachycardia was first observed after the experiment was over (Fig. 5 B). This changed into bidirectional ventricular tachycardia. P waves of sinus origin were followed by a normal-shaped QRS complex. However, the downward QRS complex was aberrant in shape, its $T$ wave being opposite in direction to the main deflection, and a compensatory pause was present (Fig. 5 C). Two minutes later sinus arrhythmia was observed (Fig. 5 D). Five records $(17 \%$ ) had such a pattern.

Pattern 6. Sinus rhythm (Fig. 6 A) changed into bidirectional ventricular tachycardia after the experiment. This was followed by ectopic ventricular activity (Fig. $6 \mathrm{C}$ and D). After eight minutes sinus rhythm recurred (strip E). In B of this figure both the QRS complexes were equi- 
A
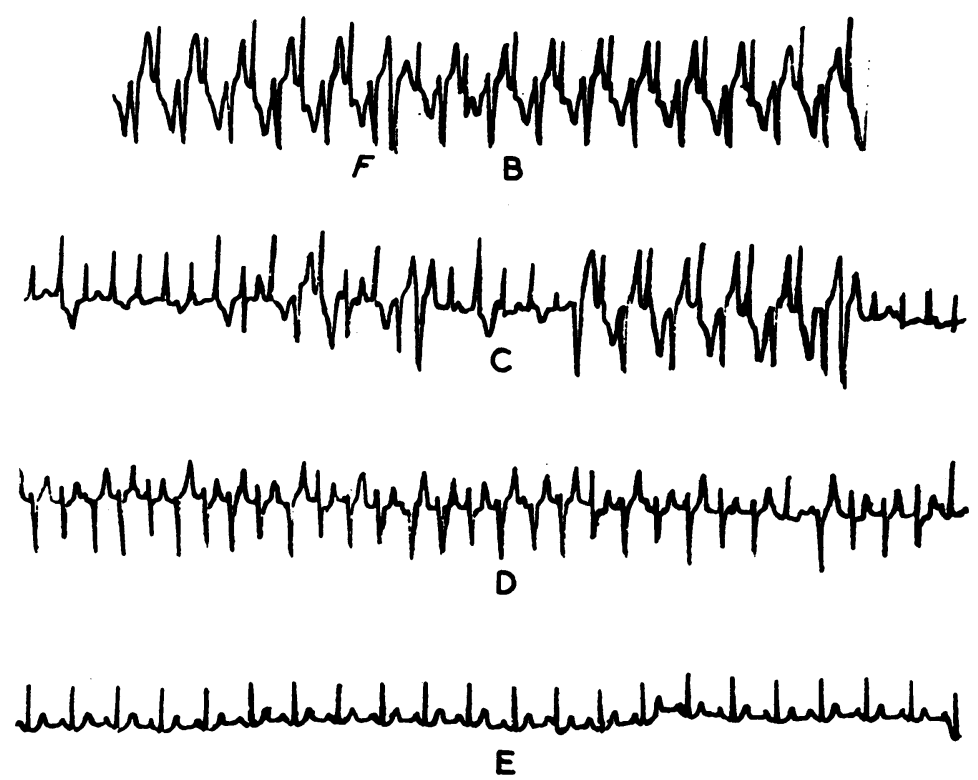

FIG. 6.- One of the graphs of pattern 6. Bidirectional ventricular tachycardia (B) appeared immediately after the experiment. This was followed by bizarre ventricular ectopic activity (C). For details see text.

distant from each other. In the course of this work $3(10 \%)$ records illustrating this observation were obtained.

Pattern 7. The control graph showed sinus rhythm (Fig. 7 A). After the experiment ventricular tachycardia developed, which in turn changed into bidirectional ventricular tachycardia (Fig. 7 B). At the arrow mark (C.S.) in this figure, carotid sinus stimulation was applied. The rhythm became irregular and was followed by ventricular tachycardia. In five experiments $(17 \%)$ this procedure

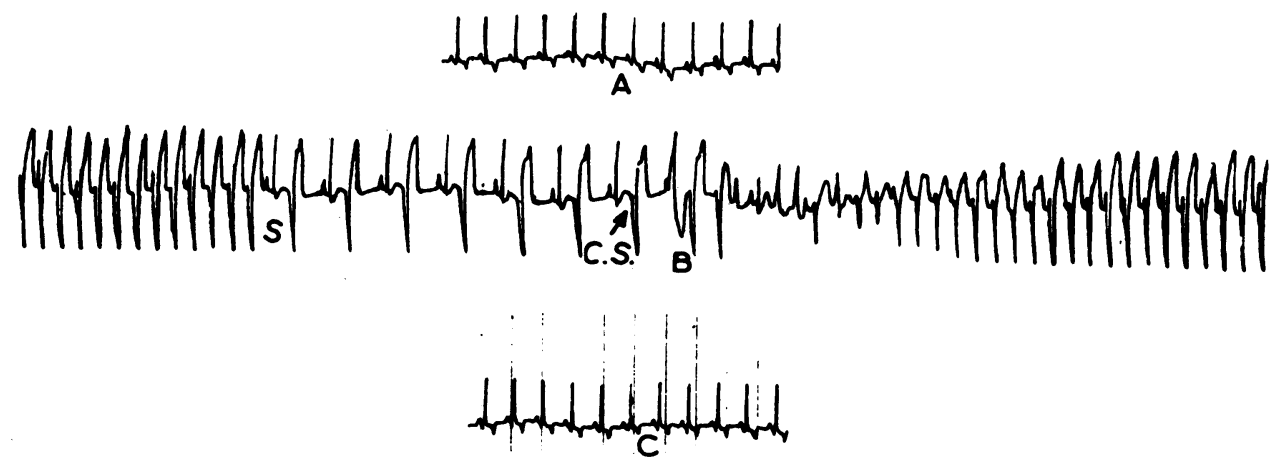

Fig. 7.-One of the records in which carotid sinus stimulation was tried. Ventricular tachycardia was followed by bidirectional ventricular tachycardia (B) of pattern 7 . For details see text. 
was tried but the change appeared in only one. This type of arrhythmia lasted for six minutes before it was followed by sinus rhythm (strip C). In this Figure exhibiting bidirectional tachycardia the upward QRS complexes were preceded by a $P$ wave and their shape resembled the QRS complexes seen in strip $A$. The downward complexes had no preceding $\mathbf{P}$ wave: they were aberrant in shape, the $T$ wave was opposite to the main deflection, and a compensatory pause was present.

\section{DisCUSSION}

The earliest belief of Schwensen (1922) that both the QRS complexes were of ventricular origin was upheld by Felberbaum (1923). He concluded that the arrhythmia was a result of independent ventricular foci alternately initiating ventricular depolarization. They discussed the possibility of this being due to hyperirritability of the ventricle resulting from the administration of digitalis. We have found six $(20 \%)$ experiments, the records of which illustrate such a mechanism. In Fig. $1 \mathrm{D}$ both the ventricular complexes are aberrant as compared with the one of sinus origin (Fig. 1 A). No $P$ waves can be seen.

Another possibility that Felberbaum (1923) and Luten (1925) considered was a single focus operating above the bifurcation of the bundle of His with aberrant conduction alternately down the left and right bundle branches. We have found four experimental records $(13 \%)$ which could be explained on the basis of this mechanism. Fig. 2 shows the origin of $P$ waves above the bundle of His: the QRS complexes are opposite in direction, and they are of abnormal shape and duration. These abnormalities may be due to aberrant conduction alternately in the right and left bundle branches.

Reid (1924), Clerc and Lévy (1926), Marvin (1928), Clarke (1930), Schwab (1931), Howard (1932), and Piloni (1936) subsequently published similar clinical case reports. They all implicated digitalis as playing an important ætiological role.

Gallavardin (1926) conceived the idea that the circus movement theory was responsible for this rhythm disturbance. He drew this conclusion from the fact that bidirectional ventricular tachycardia frequently preceded ventricular fibrillation. Palmer and White (1928) rejected the explanation that all ventricular impulses arose in one focus located above the bundle of His, because they found an alternation of the length of diastole and some irregularity in the rhythm. After discussing such possible mechanisms as parasystole and re-entry, these authors suggested that the phenomenon was due to a double ventricular circus movement.

The electrocardiographic patterns of 12 experiments $(40 \%)$ depicting bidirectional ventricular tachycardia could only be explained on the basis of two-focus theory. Three experiments had two supraventricular foci, one located in sinus and the other in A-V node (Fig. $3 \mathrm{C}$ ). The wave is of sinus origin and the QRS complex following it has the same shape and amplitude as that of the control ones (Fig. 3 A): $\mathrm{P}^{\prime}$ (inverted) is arising from the A-V node. The QRS complex associated with it is also aberrant. In the other 4 experiments out of those 12 that showed two foci of origin, one was situated in the A-V node and the other in the ventricle. In Fig. 4 C and D the upwardly directed complex is being initiated from this node and the downward from the ventricle. The remaining 5 experiments of the 12 that showed evidence in favour of double focus theory had alternately the sinus and the ventricle as the seats of impulse generation (Fig. 5).

Scherf and Kisch (1939) have dealt with the subject at length. In their opinion the circus movement theory could not be accepted as a reasonable explanation. They classified this arrhythmia into three types and offered a single focus (either supraventricular or ventricular) theory to explain the mechanism. They argued that parasystole did not appear likely as this arrhythmia always began at the same time interval from the normal beat: this fixed interval is evidence against parasystole.

Type 1 tachycardia with a regular rhythm argued against two separate ventricular foci. The action of one ectopic focus should interfere with that of the other and produce some irregularity in the rhythm unless there is a parasystolic protective block. Fig. $6 \mathrm{~B}$ of this study illustrates such a 
phenomenon. However, the objections to this theory are twofold, namely, the alternating directions of the ventricular complexes and the differing diastolic intervals. It is difficult to explain these on the basis of one-focus theory.

Evidence has been strengthened in support of single supraventricular focus by case reports of paroxysmal bidirectional ventricular tachycardia that were abruptly abolished by carotid sinus stimulation (Hellman and Lind, 1956; Schwartz and de Sola Pool, 1950; Brill, Krueger, and McCawley, 1959) and Valsalva manœuvre (Velasquez and Kelser, 1957). They concluded that the focus was of supraventricular origin because vagal stimulation had no effect on ventricular ectopic foci. We tried carotid sinus stimulation without much success and in only one of the records (Fig. 7) did the pattern of this arrhythmia revert to the previous rhythm of ventricular tachycardia. However, another explanation can be that there was an ectopic focus in the ventricle which started ventricular tachycardia (initial portion of strip B). At ' $S$ ' the sinus was trying to restore its own rhythm so that one beat was of sinus origin and the other of the ventricular origin, but as the sinus activity was disturbed by carotid stimulation (C.S.) the ventricular focus predominated producing ventricular tachycardia again.

Zimdahl and Kramer (1947) reported two cases in which carotid sinus stimulation abolished only one of the QRS complexes. The remaining QRS complex resembled ventricular premature beats which they had previously observed. They concluded that there were two foci, one supraventricular that reacted to vagal stimulation, and the others of ventricular origin.

Most of the data hitherto published have comprised clinical reports in which atrial fibrillation was usually present before the onset of bidirectional ventricular tachycardia. In the opinion of most workers, in addition to atrial fibrillation, digitalis administration was the precipitating cause of bidirectional ventricular tachycardia. It is also a common observation in clinical practice that the toxic effects of digitalis are quickly removed by simple withdrawal of this drug. Recently, Weinstein and Jick (1959) observed two cases of bidirectional ventricular tachycardia, one of which responded to calcium chelation with EDTA. In the present study also the drug-induced bidirectional ventricular tachycardia lasted until the effect of the drug had been present for nine minutes at least.

In view of these observations one cannot refrain from suggesting that the mere appearance of this arrhythmia does'not necessarily indicate a serious situation. The underlying cardiac pathology and previous rhythm disturbance have to be kept in view while assessing the prognosis.

There have been very few publications on the clinical features of these arrhythmias. Most papers describe only case reports. The explanation of the mechanism of the disorder was therefore based upon very limited observations by individual authors. One worker could only put forward evidence supporting one theory or the other. No reports of significant experimental studies have been found. However, in this work we have observed a moderate number of experiments exhibiting multiple electrocardiographic phenomena that suggest that bidirectional ventricular tachycardia is a comprehensive term embracing more than one underlying mechanism responsible for its inscription.

\section{SUMmARY AND CONCLUSION}

Two hundred mongrel dogs were subjected to the technique of Riker et al. (1955) for producing ventricular arrhythmias: of these experiments 30 showed electrocardiographic patterns of bidirectional ventricular tachycardia. The various theories propounded to explain the mechanism of its production are reviewed with reference to the cardiographic tracings obtained during the course of this study.

In conclusion it can be said that bidirectional ventricular tachycardia is only a generic term. The underlying mechanism explaining the various cardiographic phenomena varies from one observation to another. The ectopic focus may be single in some instances and double in others. It may be of supraventricular or ventricular origin, or it may arise from both sites. It is postulated 
that the prognosis may not always be bad, particularly if this arrhythmia is induced by drugs. In assessing the prognosis the basic cardiopathy should be kept in view as well as the abnormal rhythm preceding the inception of bidirectional ventricular tachycardia.

\section{REFERENCES}

Brill, I. C., Krueger, J. D., and McCawley, E. L. (1959). Restoration of sinus rhythm in experimental and clinical ventricular arrhythmias by methoxamine hydrochloride. Amer. J. Cardiol., 3, 307.

Clarke, R. M. (1930). Ectopic ventricular tachycardia. Report of a case. Calif. west. med., $32,252$.

Clerc, A., and Lévy, R. (1926). Anarchie ventriculaire. Presse méd., 34, 1073.

Felberbaum, D. (1923). Paroxysmal ventricular tachycardia: report of a case of unusual type. Amer. J. med. Sci., 166, 211.

Gallavardin, L. (1926). Tachycardie ventriculaire terminale: complexes alternants ou multiformes. Arch. Mal. Cour, 19, 153.

Hellman, E., and Lind, A. (1956). Bidirectional tachycardia. Amer. Heart. J., 51140.

Howard, T. (1932). Ventricular tachycardia with alternating complexes. Amer. Heart J., 8, 285.

Levy, A. G., and Lewis, T. (1911). Heart irregularities resulting from the inhalation of low percentages of chloroform vapour, and their relationship to ventricular fibrillation. Heart, 3, 99.

Luten, D. (1925). Clinical studies of digitalis. III. Advanced toxic rhythms. Arch. intern. med., $35,87$.

Marvin, H. M. (1928). Paroxysmal ventricular tachycardia with alternating complexes due to digitalis intoxication. Amer. Heart J., 4, 21.

Palmer, R. S., and White, P. D. (1928). Paroxysmal ventricular tachycardia with rhythmic alternation in direction of the ventricular complexes in the electrocardiogram. Amer. Heart J., 3, 454.

Piloni, U. (1936). Osservazione di un caso di tachicardia parossistica ventricolare alterna. Ann. med. nav. colon., 42, 151.

Reid, W. D. (1924). Ventricular ectopic tachycardia complicating digitalis therapy. Arch. intern. med., $33,23$.

Riker, W. F., Jr., Depierre, F., Roberts, J., Roy, B. B., and Reilly J. (1955). The epinephrine and hydrocarbonepinephrine disturbance in the cat. J. Pharmacol. exp. Ther., 114, 1.

Scherf, D., and Kisch, B. (1939). Ventricular tachycardias with variform ventricular complexes. Bull. N.Y. med. Coll., 2, 73.

Schwab, E. H. (1931). Observations on the etiology and treatment of paroxysmal ventricular tachycardia. Amer. Heart J., 6, 404.

Schwartz, S. P., and de Sola Pool, N. (1950). Transient ventricular fibrillation. Amer. Heart J., 39, 361.

Schwensen, C. (1922). Ventricular tachycardia as the result of the administration of digitalis. Heart, 9, 199.

Velasquez, J., and Kelser, G. A. (1957). Alternating bidirectional tachycardia. Amer. Heart J., 54, 440.

Weinstein, W. J., and Jick, S. (1959). Bidirectional tachycardia. Amer. J. Cardiol., 3, 343.

Zimdahl, W. T., and Kramer, L. I. (1947). On the mechanism of paroxysmal tachycardia with rhythmic alternation in the direction of the ventricular complexes. Amer. Heart J., 33, 218. 